\title{
Agroextractivismo y racismo ambiental: La industria porcícola en el estado de Yucatán
}

\section{Agroextractivism and environmental racism: The hog industry in the state of Yucatán}

\section{Agroextrativismo e racismo ambiental: a indústria de suínos no estado de Yucatán}

Atsiry López-Fabila ${ }^{1}$ https://orcid.org/0000-0001-6033-6911

\footnotetext{
${ }^{1}$ Estudiante del doctorado en Ciencias en Ecología y Desarrollo Sustentable. Orientación en Estudios de Sociedad, Espacios y Culturas. El Colegio de la Frontera Sur. Chiapas, México- atsirylfabila@gmail.com
}

Recibido: $26 / 10 / 2020$

Aceptado para publicación: 13/12/2020

\section{Resumen}

La actual crisis sanitaria ha provocado una pandemia que interpela nuestra cotidianidad y rebela no solo la fragilidad de la vida, sino la profundidad de las desigualdades estructurales sostenidas por el sistema capitalista, racista y patriarcal. Las narrativas hegemónicas de este modelo industrial funcionan como uno de los pilares Del modo de producción capitalista, promoviendo subordinaciones de La naturaleza y ciertos cuerpos, que generan procesos desiguales necesarios para El mantenimiento Del capital. A partir de La experiencia de La comunidad Kinchil y la imposición de la mega cría de cerdos, este trabajo tiene como objetivo comprender cómo la expansión de la cría de cerdos está determinando la producción de áreas de faena y cómo estos espacios se sustentan y reproducen en las formas de racismo ambiental que afecta a poblaciones que habitan estos territorios.

Palabras clave: Racismo ambiental. Agroextractivimo, Yucatán.

\begin{abstract}
The current health crisis has generated a pandemic that challenges our daily lives and reveals not only the fragility of life, but also the depth of structural inequalities sustained by the capitalist, racist and patriarchal system. The hegemonic narratives of this industrial model function as one of the pillars of the capitalist mode of production, promoting subordinations of nature and certain bodies, which generate unequal processes necessary for the maintenance of capital. Based on the experience of the Kinchil community and the imposition of mega pig farming, this work aims to understand how the expansion of pig farming is determining the production of slaughter areas and how these spaces are sustained and reproduced in the forms of environmental racism that affects populations that inhabit these territories.
\end{abstract}

Keywords: Environmental Racism, agroextractivism, Yucatán 


\section{Resumo}

A atual crise de saúde gerou uma pandemia que desafia nosso cotidiano e revela não só a fragilidade da vida, mas também a profundidade das desigualdades estruturais sustentadas pelo sistema capitalista, racista e patriarcal. As narrativas hegemônicas desse modelo industrial funcionam como um dos pilares do modo de produção capitalista, promovendo subordinações da natureza e de certos corpos, que geram processos desiguais necessários à manutenção do capital. Com base na experiência da comunidade Kinchil e na imposição de uma mega suinocultura, este trabalho objetiva compreender como a expansão da suinocultura está determinando a produção de áreas de abate e como esses espaços são sustentados e reproduzidos nas formas de racismo ambiental que atinge as populações que habitam esses territórios.

Palavras-chave: Conflito capital-vida. Corpo-território. Abya Yala

\section{Introducción}

El presente trabajo surge de la preocupación por entender el entramado que existe entre la expansión de la agroindustria porcícola, las formas de racismo ambiental que sirven de pilar para su sostenimiento y que subsumen la vida al servicio del capital, y la producción de zonas de sacrificio caracterizadas procesos de despojo y daño ambiental que atentan contra la salud, los cuerpos y la vida, en particular de personas indígenas, afrodescendientes, campesinas y prietas.

Las reflexiones que desarrollo en las siguientes líneas buscan contribuir a la desarticulación de la tesis que sostiene que los riesgos y daños ambientales se viven de la misma forma para todos los cuerpos independientemente de la clase social, la raza y el género, y el medio ambiente como un moldeador neutro que afecta de la misma manera la experiencia de todos los seres humanos.

En este contexto la experiencia de la comunidad de Kinchil en el poniente de Yucatán frente a la imposición del megaproyecto porcícola, permite explorar las formas de racismo ambiental que afectan a la población y sus territorio. Y como las decisiones, prácticas y discursos contribuyen a una política de construcción de territorios de sacrificio bajo un modelo extractivo.

En este sentido analizo los procesos de despojo provocados por la agroindustria porcícola desde la noción de zona de sacrificio y racismo ambiental. Algunas interrogantes que guían este trabajo son ¿Cómo la expansión de la agroindustria porcícola determina la 


\section{LÓPEZ-FABILA, A.}

producción de zonas de sacrificio? ¿y cómo estás geografías se sustentan y reproducen formas de racismo ambiental que afectan a los territorios y cuerpos de personas no blancas?

Para abordar estos cuestionamientos en un primer momento presento una breve revisión conceptual y teórica de las zonas de sacrificio y el racismo ambiental para brindar una aproximación a los contextos desde los cual estas nociones han surgido. Posteriormente presentó algunos datos sobe el crecimiento de la agroindustria porcícola en el estado de Yucatán para dar cuenta de su crecimiento y expansión, así como los principales daños ambientales por lo que ha sido señalada. En un tercer apartado, planteo la ideas de la agroindustria porcícola como productora de geografías de racismo ambiental basada en la territorialización de zonas de sacrificio. En un cuarto momento, desarrollo, el potencial que tienen las contranarrativas de los pueblos mayas que han funcionado para señalar y nombrar y develar los procesos de despojo basados en el racismo ambiental y que han sido contantemente revestidas del discurso del progreso y desarrollo.

\section{Zonas de sacrificio y racismo ambiental: aproximaciones teóricas}

Hablar en clave de sacrificio es decir que en aquellos espacios en los que el capital ocupa despoja, la vida queda subsumida a la muerte. El sacrificio como señalan VelaAlmeida, Zaragocín, Bayón, y Arrazola (2020) es un elemento intrínseco a la producción del territorio y del espacio nacionales. El capital toda vez que busca separar, fragmentar el tejido de la vida implica pensar la vida como un territorio descartable, como espacio de sacrificio resultado de los costos inevitables del progreso donde se produce muerte para poder adecuar los espacios para el capital. Haciendo uso de la idea de necropolítica de Achile Mbembe (2003), se establece una reconfiguración de la vida a través del establecimiento de una política de la muerte que rige la cartografía de los territorios en donde se despliegan mecanismos, prácticas e ideologías que establecen un jerarquización que marca la línea divisoria entre uuién importa y quién no, quién es desechable y quién no.

Las zonas de sacrificio, como se han nombrado aquellos territorios en lo que por diversas razones sociales, económicas y políticas han sido objeto de políticas de desarrollo extractivistas al punto de generarles una degradación. Esencialmente estos lugares se caracterizan por la contaminación industrial del aire, del agua y del suelo, problemáticas ambientales que resultan de la insustentabilidad del modelo hegemónico de desarrollo. Como señalan Firpo Porto, Pacheco, y Leroy, (2013) en estas zonas se ponen a disposición del capital los bienes comunes por lo que también se consideran zonas de sacrificio social, en las 


\section{LÓPEZ-FABILA, A.}

cuales se niegan derechos fundamentales. A través de la violencia como mecanismo de configuración, se adecua estos espacios a los necesidades de grandes emprendimientos y de los grupos sociales históricamente privilegiados.

En la conformación de las zonas de sacrificio en el territorio,-entendido como un espacio de intimidad, de protección, donde se reproducen también los vínculos sociales y familiares-(Colectivo Miradas Críticas del Territorio desde el Feminismo, 2014) suceden rupturas y discontinuidades que se expresan en el total de los procesos de reproducción de la vida. Es decir estas rupturas no suceden solo en la expropiación del agua, el bosque, la selva sino que también permean y se expresan en la transformación de las relaciones de interdependencia que tienen lugar entre la naturaleza y las comunidades y en el conjunto total del entramado comunitario.

$\mathrm{Al}$ quitarles su usos, funciones y por ende el rol constitutivo que tienen en la recreación de las comunidades; provocan la constitución de territorios fragmentados, insustentables e inherentemente incompatibles con el bienestar y la salud de los territorios y los cuerpos, en donde se expresan desigualdades sobre los procesos de salud, vida y muerte. Son zonas que reflejan la contradicción que constante en nombre del 'orden', de la seguridad de algunos pocos y del 'progreso', sistemáticamente se niega la vida para quienes deben asumir los costos del desarrollo (Borde y Torres-Tovar, 2017).

El reconocimiento de estas zonas por parte del Estado y el capital nunca son asumidas, por lo que es importante señalar la participación y la responsabilidad histórica del Estado que al no reconocer el daño acumulado permite la naturalización de la contaminación (Bolados y Sánchez, 2017).

Con respecto a la denominación de las zonas de sacrificio la experiencia de las mujeres organizadas en la zona de sacrificio de Puchuncaví-Quintero, en la zona central de Chile han interpelado el concepto mismo desde las acciones que han realizado en el espacio público y privado con las cuales cuestionan las narrativas de "sacrificio" que se han impuesto sobre quienes se oponen al sacrificio de sus territorios. Como contranarrativas de resistencia han desplegado la implementación de políticas de vida, encaminadas a una ética del cuidado que pone en evidencia cómo los procesos de ruptura provocados por el extractivismo y el patriarcado se expresan tanto en los territorios como en los cuerpos (Bolados García et al., 2017). Así mismo interpelan está noción señalando lo vital de abandonar la denominación "Zona de Sacrificio" y establecer una "Zona de Recuperación, Justicia y Bienestar, en su propia voz establecen "aquí nada ni nadie está despojado de dignidad y valor humano, como 
LÓPEZ-FABILA, A.

para que sus derechos fundamentales como vivir en un ambiente libre de contaminación sea sacrificable” (Orellana Sepulveda, 2018, p.46)

Así mismo desde otros movimientos de mujeres en los territorios existen nociones distintas que aportan al entendimiento, la critica y la resistencias a los proyectos de muerte impuestos por el capital para señalar las políticas de la muerte que tienen lugar. En este sentido mujeres indígenas organizadas en el movimiento por el buen vivir articulan desde sus experiencias el concepto de Terricidio, cuñado por Moira Millán, el cual nombra el "aniquilamiento de la vida en los territorios, la vida de sus pueblos, y de la ancestralidad que encarnan, y que debe ser considerado y tratado como crimen de lesa humanidad" (Intervención de representantes de pueblos originarios en defensa de la Amazonía durante la COP25 en Descolonizar el ecologismo, 2019).

El racismo como sistema totalizante y estructural, se basa en la creación de jerarquías de superioridad e inferioridad que han servido como medidas regulatorias de dominación y opresión sobre el otro. El racismo como refiere Mónica Figueroa (2016) es un "criterio que establece los parámetros de inclusión y exclusión, de privilegio y opresión". Retomando a Hartaman (2007, p.92).) la autora precisa que el racismo determina "la distribución social de la muerte; como una gráfica actuarial, predice quien va a florecer y_quien no"

Como proceso social histórico el racismo es reinventado y transformado en diversos contextos, por lo que podemos hablar de una multiplicidad de formas de racismo, y por tanto concebirlo como un proceso variable y heterogéneo.

En específico cuando se habla de racismo ambiental, se refiere a una forma de discriminación institucional que se materializa a través de políticas, prácticas, o directivas que afectan de manera diferente y de forma desaventajada a individuos, grupos o comunidades sobre la base de su identidad étnica o racial (Bullard, 2002 en De Oliveira Pires, Thula Rafaela; Totti Guimaraes, 2001). El origen de está noción se ubica en el contexto de las luchas por la justicia ambiental durante la década de 1980 las cuales señalaban la desigual exposición a riesgos ambientales y sus impactos, que afectaba de manera negativa a comunidades de color en Estados Unidos (Bullard, 1993), la focalización deliberada para depósitos de desechos tóxicos en comunidades de color, la autorización oficial de la presencia de venenos que atentan contra la vida y substancias contaminantes en las comunidades de color, y la exclusión de la gente de color del liderazgo del movimiento ambiental (Chavis en Moreno Parra, 2019, p.91) 


\section{LÓPEZ-FABILA, A.}

El racismo no es una entidad estática, se reconstruye, reinventa y extiende a diversos dimensiones de la existencia humana. En este sentido al abordar el estudio del racismo ambiental es necesario hacer énfasis en no reducirlo a la concepción de un acto individual de discriminación o a una hostilidad. Delimitarlo a estas prácticas e interpretaciones implica olvidar las formas estructurales y hegemónicas de racismo en la contribución de las desigualdades (Pulido, 2000).

Contemplar la exposición desproporcionada de los daños ambientales sin reconocer explícitamente el marcador racial, como señalan (De Oliveira Pires, Thula Rafaela; Totti Guimaraes, 2001) "significa no afrontar adecuadamente el modelo de dominación que fue erigido, lo que contribuye a perpetuar la invisibilidad de ciertos cuerpos, de ciertas formas de vida y visiones del mundo". Así mismo estas autoras refieren el movimiento de justicia ambiental en Brasil, ha buscado incorporar además de la raza y el nivel de ingreso, otros aspectos como el acceso a servicios, infraestructura urbana, nivel de educación y otros indicadores que pueden dar un visión más amplia que permita develar las intersecciones entre riesgo y vulnerabilidad ambiental, derechos y ciudadanía, o entre localización y grupo étnico.

\section{La industria porcina en Yucatán}

Posterior al declive de la producción del monocultivo de Henequén, principal enclave económico para la expansión de un modelo que se basó en la explotación de la fuerza de trabajo de los y las mayas que perduro hasta mediados del siglo $\mathrm{XX}$, En un intento por diversificar la zona y el agronegocio, la agroindustria porcícola empezó a tener mayor presencia en la región. En 1969 el gobierno del estado de Yucatán promovió entre algunos campesinos la crianza de puercos, a través de un sistema familiar de producción, momento considerado como la primera etapa en la que esta actividad se empieza a consolidar. Durante la década de los 90 con la entrada en vigor del Tratado de Libre Comercio, la producción de carne de cerdo empezó a tener un crecimiento acelerado ante la entrada de México al mercado mundial de exportación de carne. Así mismo en el estado de Yucatán también se da la apertura del mercado de exportación, siendo el Grupo Porcícola Mexicano la primer empresa en exportar carne de cerdo a Japón.

Actualmente el estado de Yucatán representa uno de los principales productores de carne porcícola a nivel nacional y el principal en la región Sureste de México. El aumento de su producción responde a un crecimiento vinculado a la expansión de los agronegocios 


\section{LÓPEZ-FABILA, A.}

principalmente con el aumento de la siembra de monocultivos como la soya, sorgo y palma de aceite. El "modelo Kekén" establecido por el Grupo Porcícola Mexicano, principal empresa dedicada a la producción y comercialización de carne de cerdo, se basa en la interconexión entre diversos proyectos de agronegocio que consiste en el encadenamiento productivo, incluye la siembra de soya, su procesamiento y el consumo en granjas porcícolas y avícolas. La implementación de este modelo ha sido impulsada por la Asociación de Porcicultores de Mérida mediante contratos de aparcería con los productores (Flores y Deniau, 2019). Bajo el esquema de aparcería se integra a los campesinos (aparcero) a manera de "socio" de la empresa, la cual le entrega los cerdos a fin de que los cuide y alimente bajo sus especificaciones, técnicas de manejo e instalaciones. Está modalidad es una de una de las principales estrategias para la industrialización y reestructuración de la agricultura, bajo la cual los agronegocios han visto una ventaja para territorializar el despojo y acaparamiento mediante la flexiblización en los costos de producción, un abaratamiento de la mano de obra, reducción en inversiones y deslinde de responsabilidades frente al daño ambiental.

Para situar en términos de cifras el crecimiento de la agroindustria porcícola en Yucatán, según cifras del Servicio de Información Agroalimentaria y Pesquera (SIAP) hasta septiembre de 2019, se encontraba debajo de los estados de Jalisco, Sonora y Puebla, con una producción de 147,064 toneladas aportando 9\% a la producción nacional. En cuanto al número de megagranjas de las 257 registradas oficialmente, 222 se encuentran en Yucatán, es decir el $86 \%$ de las granjas de la Península se concentran en este territorio sobre todo en los municipios que se encuentran alrededor de la ciudad de Mérida (Geocomunes y Consejo Civil Mexicano para la Silvicultura Sostenible, A.C y Martínez Zazueta, 2019).

\section{Daños ambientales: rupturas de la vida provocadas por la industria porcícola}

“[...]Están por cientos las granjas en la Península y conectan un tubo para que los desechos se vayan al cenote, ya le dieron en la torre a la tierra, al agua, al aire. Entonces también es un montón de tierra que agarran, por que si bien es cierto digamos que agarra un área de 100 hectáreas pero el olor de esa onda, por ejemplo si tu corres de Muná hasta Yaxcopoil, estoy hablando como de $40 \mathrm{~km}$, todo esos $40 \mathrm{~km}$ vienes sintiendo el olor a caca de cochino y no ves ninguna granja, están metidos en el monte. Entonces también eso es dañar el ambiental, cómo puedes decir estoy viviendo en un ambiente sano ¿y los niños? ¿y las mujeres? ¿y la reproducción del ser humano y de los otros animales?" (entrevista con Pedro Uc Be, integrante de la Asamblea Múuch Xíinbal, entrevista, marzo 2020).

Las implicaciones sociales, ambientales, económicas y de salud que conlleva el crecimiento acelerado de la industria porcícola han sido documentadas en diversas territorios. 


\section{LÓPEZ-FABILA, A.}

Robert Wallace (2016) en Grandes granjas hacen grandes gripas señala la conexión entre las corporaciones agroalimentarias y el surgimiento de virus que han ocasionado pandemias como la gripe porcina (AH1N1) y la gripe aviar (SARS). La transmisión de enfermedades en estas condiciones surgen en condiciones de nulo bienestar social y en situaciones de hacinamiento de animales los cuales están expuestos múltiples enfermedades las cuales para prevenirlas requieren de la aplicación de una gran cantidad de antibióticos y antivirales que generan resistencias cada vez más fuertes, siendo estos espacios como menciona Silvia Ribeiro "fabricas de replicación y mutación de virus".

En el contexto nacional de México es importante no perder de vista el antecedente sobre Granjas Carroll en Cofre de Perote, Veracruz empresa propiedad de la compañía estadunidense Smithfield Foods que desde su llegada en 1994, ha ocasionado contaminación de cuerpos de agua, del suelo, riesgos sanitarios por las grandes cantidades de desechos químicos y microbianos, enfermedades sobre la población, acaparamiento y despojo del agua, desplazamientos forzados y acoso judicial sobre las comunidades que han sido afectadas. Organizados en la agrupación Pueblos Unidos, comunidades de la región denunciaron los graves daños ambientales y la generación de enfermedades respiratorias, gastrointestinales y cutáneas que la población estaba sufriendo a consecuencia de Granjas Carroll. Así mismo, durante el año 2009 campesines de La Gloria señalaron que está comunidad era el epicentro del virus de la influenza H1N1, Edgar de cinco años fue la primer persona identificado con influenza porcina (GRAIN, 2009).

En Yucatán, diversas comunidades entre ellas Homún, Maxcanú, Celestún, Chapab, Sotuta, Sudza y Kinchil han externado y señalado los graves impactos que han ocasionado las granjas de cerdos sobre la salud del territorio y las poblaciones. Particularmente las preocupación y demandas se centran en exaltar la rupturas que la industria porcícola está ocasionando sobre los procesos de reproducción de la vida, en particular la amenaza que representa para los cuerpos de agua como son los cenotes. La expansión de estas zonas porcícolas, amenaza a una de las mayores reservas de agua subterráneas más importante, la Reserva Estatal Geohidrológica Anillo de Cenotes promulgada en el 2013 y la primera de su tipo en el estado. De acuerdo al trabajo realizado el coletivo Geocomunes (Flores y Deniau, 2019) la producción porcícola en la península de Yucatán posee la concesión sobre 143 pozos y un volumen de 13,1 millones de metros cúbicos; destacando el Grupo Porcícola Mexicano (Kekén), como el principal acaparador, con el $46 \%$ del volumen de agua y el $49 \%$ de los pozos concesionados. 
LÓPEZ-FABILA, A.

Particularmente la generación de desechos de las aguas residuales que se producen como resultado de toda la cadena de producción es una de las principales fuentes de contaminación por materia orgánica en la región (Druker et al 2003). De acuerdo con los reportes del Consejo Nacional de Población en 2010, la zona porcícola presentaba una contaminación por desechos pecuarios seis veces mayor que la que puede producir la población humana asentada en ese lugar (Indignación, 2020).

En Yucatán la actividad porcina genera $2.98 \mathrm{hm}^{3}$ por año de aguas residuales, de las cuales el $63 \%$ recibe parcialmente algún tratamiento, principalmente conformado por granjas grandes y $37 \%$ no recibe ningún tratamiento .En cuanto a la producción de excretas y purines, los cerdos excretan entre 60 y $80 \%$ de nitrógeno $(\mathrm{N})$ y fósforo (P) ingerido, cuando estos sobrepasan los límites máximos permisibles (Rodríguez-León, Ordoñez-Vásquez, y QuizhpeCordero, 2019), Su acumulación y mal manejo provoca una alteración del pH de los suelos debido a las altas concentraciones nutrientes así como la infiltración al subsuelo de nitratos. La acumulación de metales pesados en la capa superficial del suelo, particularmente por la presencia de sales de hierro y cobre (Novelo et al., 2009) es otra problemática que impacta a los suelos de la región.

Los suelos de Yucatán al ser de naturaleza porosa poseen un alta permeabilidad que genera procesos de infiltración rápida hacia las aguas subterráneas que se encuentran a poca profundidad por lo que la acumulación de estos componentes representan un riesgo inminente para la población ya que una vez que son depositados en los suelos rápidamente son filtrados al subsuelo y de ahí pueden ser consumidas por las personas que se abastecen del agua proveniente de los cenotes y pozos (Drucker et al., 2004). La presencia de esos nitratos en los sistemas públicos de abastecimiento constituye un riesgo para la salud de las personas al producir compuestos llamados nitrosaminas, que son cancerígenos para el estómago y ocasionan problemas respiratorios (Pacheco Ávila y Cabrera Sansores, 2003). Uno de los estudios más reciente en cuanto a la calidad del agua en sitios con presencia de granjas porcinas, se realizó en 2019 por Greenpeace y la Universidad autónoma de Campeche, en dicho estudio tomaron muestras de agua de cinco pozos y un cenote de cuatro municipios (Kinchil, Maxcanú, Opichén y Chocholá) y los resultados arrojaron que todas las muestras excedían los mites recomendados de amonio, nitritos y nitratos según los estipulado en la NOM-127-SSA1, la cual determina los limites recomendados para uso y consumo humano.

\section{Kinchil, diez años de racismo ambiental}




\section{LÓPEZ-FABILA, A.}

"Se nos fueron perdiendo los animales, ya no entraban a los corrales teníamos vacas embarazadas y de pronto ya no las vemos no regresa la vaca con el becerro entonces pues salimos a caminar esos montes y en esas caminatas tan largas no topamos un buen día que nuestros alambres estaban en el suelo y de pronto me tope con unos pantanos verdes, de agua verde. Esos montes los habíamos caminado durante mucho tiempo, bueno ahí es nuestra tierra pues, entonces, no existían esos pantanos y era tan grande el pantano y vimos los arboles muertos" (Alberto Rodríguez Pisté, poblador de Kinchil, entrevista 2020)

El municipio de Kinchil posee una población de 6,571 habitantes donde 93.6\% se nombra e identifica como indígena. De acuerdo a los datos sobre la situación de marginalidad en Kinchil muestran que $65.1 \%$ se encuentra en situación de pobreza y $12.8 \%$ en pobreza extrema (CONEVAL, 2015).

En el contexto de la pandemia de COVID-19, las condiciones de desigualdad se han profundizado y exacerbado la vulnerabilidad de ciertas poblaciones, tal es el caso de las comunidades indígenas quienes ante la falta de infraestructura y escaso acceso a la salud han sufrido mayores pérdidas de vidas y exposición al contagio. Hasta junio de 2020, Yucatán se considera la entidad con mayor número de casos positivos y defunciones por COVID-19 con 250 contagios positivos acumulados y alrededor de 50 muertes (Chablé Méndoza, 2020). De acuerdo a datos del Visor geoespacial de la pobreza y COVID-19 en los municipios de México (2020), el municipio de Kinchil considerado como municipio con un alto porcentaje de pobreza, presentó hasta octubre 2020 registró 29 casos activos de COVID, 7 defunciones, 17 recuperados y 1 caso activo.

En cuanto a los niveles de analfabetismo de la población de 15 años o más presenta un $14.21 \%$, el doble del porcentaje a nivel estatal con una marcada brecha entre hombres y mujeres (43.48\% vs 57.22\%). Sobre el acceso a los servicios básicos, $96 \%$ cuenta con agua entubada a través del servicio público y $3.05 \%$ se abastece a través del acarreo, siendo los pozos los principales puntos de abastecimiento para esta población (94.06\%). Aunque el porcentaje registrado parece ser bajo, es importante señalar que los pozos representan una fuente importante de consumo de agua, mismos que están siendo amenazados por la presencia de las granjas y en los cuales existe evidencia del daño que presentan debido a la contaminación a la que han sido expuestos. Por otro lado $53.63 \%$ disponen de drenaje, de los cuales $99.71 \%$ utilizan fosa séptica como lugar de desalojo, mientras que $46.23 \%$ no dispone de drenaje y $40 \%$ de las viviendas, según los índices de Marginación de CONEVAL no disponen de excusado o sanitario dan cuenta (INEGI, 2015). 
LÓPEZ-FABILA, A.

A diez años del establecimiento de Kekén en tierra Kinchileña, se han desplegado en el territorio prácticas de racismo ambiental ligadas al despojo territorial y la afectación de la vida de las personas legitimadas por el abandono y desinterés por parte del Estado. El hallazgo de cuerpos de agua contaminados entre los montes de Kichil, la disminución de la población de abejas y de la cosecha de miel, la pérdida de animales, la muerte de árboles importantes para la región como el palo tinte, a causa de la imposición del complejo agroindustrial porcino de Kekén, han sido sucesos que han detonado movilización, la denuncia y la articulación, con otras comunidades como Celestún, Maxcanú, Sisal, Hunucmá, Halacho y Homún que también viven la afectación de sus territorios.

El uso de dispositivos expropiatorios como hacen referencia (Composto y Navarro, 2014) al conjunto de estrategias que despliegan las empresas y el gobierno para instalar la lógica del modelo extractivo en los territorios y entre sus poblaciones, que van desde la legalidad institucional; el consenso y legitimidad; la cooptación y captura; el disciplinamiento y la normalización; la criminalización y represión y finalmente la militarización y contrainsurgencia. Han funcionado como medios para negociar/administrar la violencia que simultáneamente se ejerce contra el cuerpo y el espacio (Zaragocin, 2020).

En el caso de Kekén, las comunidades han señalado mecanismos que podríamos nombrar la aplicación de dispositivos expropiatorios que han sido funcionales a las zonas porcícolas, como son la cooptación de lideres comunitarios, compra de tierras, división comunitaria y acuerdos con dependencias estatales y gobiernos en turno, y utilización de marcos institucionales para su imposición de forma ilegal. Por ejemplo, sobre la operación y funcionamiento de las granjas, el Informe Greenpeace señala que 90\% de las granjas porcinas operan de forma ilegal en toda la península de Yucatán. Del total de 257 solo 22 granjas cuentan con manifestación de impacto ambiental, no cuentan con reportes de las emisiones y transferencia de contaminantes ante el registro de Emisiones y Transferencia de contaminantes ante la Secretaria de Medio Ambiente y Recursos Naturales (SEMARNAT) y tienen inconsistencia en el trámite y gestión de los permisos de aprovechamiento de agua y descarga (GREENPEACE, 2020).

Durante el 2017 integrantes de Chik'in-Já realizaron la presentación de una denuncia popular interpuesta ante la Procuraduría Federal de Protección al Ambiente (PROFEPA), ante la SEMARNAT, ambas del gobierno federal, así como ante la Secretaría de Desarrollo Sustentable del Gobierno de Yucatán. La denuncia constituye una experiencia relevante en la defensa del territorio frente a la expansión del agronegocio porcícola que además de exponer 


\section{LÓPEZ-FABILA, A.}

las acciones y omisiones que han provocado deforestación, desequilibrio ecológico anunció la conformación del Consejo Maya del Poniente de Yucatán Chik’in-Já (Agua del Poniente).

Organización fundamental para la visibilización y señalamiento especialmente en lo que respecta a su derecho a ser consultados sobre el proyecto, tal como es garantizado por el derecho fundamental al consentimiento libre, previo e informado. Como parte de denuncia popular se ha enfatizado esta cuestión señalando que quienes tienen la facultad de decidir, cuidar o autorizar cualquier actividad que quiera realizarse sobre su territorio son los pueblos mayas. Durante este evento Alberto Pisté, vocero del consejo señaló:

"Aquí lo interesante es que a nosotros como pueblo maya, como pueblo originario nadie nos pregunto si ellos podían poner una granja así, desconocemos las razones, los permisos. Queremos saber quien otorgo esos permisos, quien firmo eso a lo que llaman MIA, quien firmo esos manifiestos de impacto ambiental, queremos saber si realmente se hizo un estudio de impacto ambiental, queremos saber realmente de que manera ellos se apoderaron de estas tierras, ... si a nosotros como gente local nos han hecho tantas trabas para nuestras solicitudes de cambio de uso de suelo porque ellos si lo lograron en tan poco tiempo? ¿quién está atrás de esto? ¿Por qué atentan con nuestras vidas?, ¿por que atentan con el futuro de los mayas?, ¿por qué atentan con la vida de los niños?[...] todo esto nos inquieta no asusta".(informacion verbal) ${ }^{2}$

Las palabras de Alberto Pisté demuestran con claridad la ausencia de la voz de los pueblos mayas sobre la decisiones sobre su propia vida. El desplazamiento de las poblaciones en la participación y en el derecho a decidir sobre sus territorios hace posible identificar estas características como un rasgo inherente al racismo institucional que tienen lugar en la conformación de las zonas de sacrificio. Dando lugar a su exclusión en la participación política y sobre todo el nulo se respeto a la libre determinación de los pueblos. Tales dinámicas repercuten y afectan a las comunidades quienes cada vez más se enfrentan a la pérdida de su autonomía territorial (Colectivo Miradas Críticas del Territorio desde el Feminismo, 2017).

La implementación de las megagranja de Kekén en Kinchil mantiene en una narrativa que presentan con frecuencia las empresas extractivas, las cuales ofrecen la generación de empleos que por lo general son temporales y mal remunerados y que continúan reproduciendo jerarquías racializadas siendo las personas de las comunidades indígenas, afro, mujeres; quienes ocupan los trabajos mayormente precarizados al no ser considerades como mano de obra cualificada por la empresa. En la experiencia de Kinchil los trabajos que se ofrecieron a la población se dieron principalmente durante la etapa de inicial de la

\footnotetext{
${ }^{2}$ Consejo Maya del Poniente de Yucatán Chik’in-Já, Alberto Pisté, vocero del consejo 


\section{LÓPEZ-FABILA, A.}

construcción de las naves porcícolas. Principalmente los hombres fueron empleados para limpiar los terrenos, construcción de las cercas y las divisiones del terreno.

La agroindustria porcícola no ha sido la excepción y a partir del uso de discursos sobre la ubicación geográfica estratégica de Yucatán como espacio “aislado" del resto del territorio nacional, se ha servido para promover su expansión territorial y justificación como actividad necesaria para el desarrollo económico y del progreso moderno del Estado. Como parte de esta narrativa expresan que su "crecimiento y expansión representa beneficios para las comunidades que intervienen en sus procesos, pues los empleos que generan no se concentran en un solo lugar, sino que se ven reflejados en diferentes regiones del territorio de tal forma que los beneficios son considerados como parte de sus grandes propósitos en materia de desarrollo económico y social y para el beneficio del estado” (Impulso porcícola, 2018).

En esta misma dirección, el uso de estas narrativas que justifican su existencia son empleadas de manera consistente como parte del proyecto agroextractivista. Durante una entrevista realizada a Claudio Freixes, director general de Kekén publicada por la Revista de Comercio exterior sobre las características que hacen de Yucatán un "lugar atractivo" para la producción de cárnicos" señaló que Yucatán al ser un espacio geográfico relativamente aislado del resto de la república, ofrecía condiciones sanitaras convenientes para el desarrollo de la agroindustria. Así mismo como parte de estas ventajas consideran que su ubicación privilegiada les otorgaba acceso a la desembocadura del río Mississippi, otorgando una conexión comercial para el abastecimiento de grano norteamericano que llega a el Golfo de México.

Esta declaración que desde un lectura simple parece solo nombrar las ventajas que en términos comerciales obtiene la agroindustria, expresa la ideología y las políticas que constituyen los territorios inmateriales del capital. Territorios que como señala (Machado Aráoz, 2012) son diseñados por y mediante la inversión que produce territorios "nuevos", "territorios eficientes, productivos, rentables, competitivos" configurados tal forma que puedan ser funcionales al capital. La base de estas narrativas se sustentan y se deben a una matriz históricamente colonial de extracción y dominación que media la producción de sentido y imaginarios desde las cuales se definen a los territorios indígenas, campesinos, rurales como territorios baldíos, ociosos, pobres, que deben de ser ocupados e incorporados al proceso de modernización y progreso.

La instrumentalización de tales narrativas han dado forma a la ideología espacial del Estado-Nación con las cuales se invisibiliza los sacrificios en aras de un "bien o progreso 


\section{LÓPEZ-FABILA, A.}

nacional" que legitima intervención de las empresas y permiten que ingresen a las comunidades de manera fraudulenta, motivando a la parcelación de tierras ancestrales (VelaAlmeida et al., 2020).

El discurso colonial basado en la discriminación racial de las poblaciones indígenas de Yucatán como "grupos minoritarios rebeldes que no están por el entendimiento", como se refiriera el director de Kekén a las y los pobladores de Homún y Kinchil, así como contra activistas, que protestaron en contra de la empresa durante el 2019 en el marco Cumbre Mundial de los Premios Nobel de la Paz en Mérida (Rejón Katia, 2019). Poner énfasis en las ideas que se expresan en los discursos públicos resultan útiles para comprender efectos de las ideas y las palabras en los actos, como puntualiza ubicar a los sujetos reproductores de estas ideas y discursos permite dar cuenta de que no son actos individuales que recaen sobre el sujeto sino que existe una dinámica mucho más profunda del racismo que se repite históricamente y se mueve desde el plano ideológico hasta la práctica, pasando por los estereotipos y prejuicios. Desde estos discursos como menciona (Moreno Parra, 2019) se continúan y refuerzan las jerarquías etnorraciales que devalúan las vidas, cuerpos y experiencias de las personas indígenas, campesinas, afrodescendientes.

La experiencia de la comunidad de Kinchil y la imposición del megaproyecto porcícola de Kekén, ejemplifica los mecanismos para entender la implementación de los despojos territoriales ligados a formas de racismo ambiental; a través de los cuales se ha buscado adecuar el territorio a las necesidades de los grandes emprendimientos, a la demanda de bienes materiales por parte de las ciudades y en general como medios para responder a las necesidades de los grupos históricamente privilegiados. Los procesos de degradación ambiental ligados al despojo configuran un territorio de malestar atravesado por una serie de transformaciones que modifican tanto el territorio como la propia existencia humana.

Dichos procesos perfilan el territorio como zona de sacrificio que ha sido designado por el capital como espacio de acumulación del agroextractivismo porcícola donde se "ha provocado la alteración de los ciclos de la naturales y una fractura en el equilibrio de la naturaleza" (Alberto Pisté, campesino, apicultor y poblador de Kinchil), y en el que las externalidades del modelo han sido impuestos hacia la población indígena de Kinchil. Quienes enfrentan y viven el sufrimiento ambiental y los daños de forma desproporcionada en comparación al resto de la población.

Es decir el sacrificio que se ofrenda al altar del desarrollo no es sufragado de la misma forma por todos los cuerpos, responde a cierto perfil particular de las personas que no es 
LÓPEZ-FABILA, A.

gratuito, son aquellos cuerpos que han sido racializados como indígenas, negros, prietos, cuerpos no blancos quienes lo sostienen. Cabe preguntarse ¿por qué los lugares que elige la industria porcícola coincide con territorios perteneciente a las comunidades mayas?.

\title{
Contracartografías al sacrificio: "Los reconocemos y los señalamos"
}

¿Cómo voy a permitir que mi nieta tome agua contaminada? no, pu.es no lo voy a permitir"

(Don Doro, guardián de los cenotes , ka'anan ts'onot. Entrevista, marzo 2020)

\begin{abstract}
Las manifestaciones de rechazo a la imposición, extractivismo y daño ambiental que las granjas porcícolas están provocando en los territorios de Yucatán constituyen diversas expresiones de resistencias que representan un esbozo de lo que podríamos nombrar como contracartografías al sacrificio, puesto que interpelan y cuestionan la estructura jerárquica de la temporalidad-espacialidad, que no solo justifica la relación poder-saber, sino que permite el despojo y extracción de la vida en territorios de pueblos indígenas declarándolos vacíos, ociosos, aislados (Cevallos y Cevallos, 2018).
\end{abstract}

Frente a estas disputas, estas contracartografías construyen y buscan posibilidades otras de hacer espacios que confronten el sacrificio. En este sentido, brevemente quiero mencionar algunas de las acciones parten de la organización de comunidades en Yucatán que están haciendo frente a los proyectos porcícolas industrias que desde las territorialidades tensionan la producción de los espacios del capital, al denunciar sus falsas promesas así como la relación intrínseca con la injusticia y la violencia (Vela-Almeida et al., 2020).

A finales de 2016 en la comunidad de Homún la empresa Producción Alimentaria Porcícola, conocida como PAPO arribo al territorio con la finalidad de instalar una megagranja con el aval de la la Secretaría de Desarrollo Sustentable quien aprobó una Manifestación de Impacto Ambiental en la que se estipulaba el establecimiento de una instalación con una capacidad de 50 mil cerdos (Indignación, 2020). Ante la preocupación del desarrollo de este proyecto sobre una de las reservas de agua dulce más importante en México, la Reserva geohidrológica del “Anillo de los Cenotes”. Surgió Kanan Ts'ono'ot (Guardianes de los Cenotes) un movimiento referente en el Sureste, por ser la primer comunidad en expulsar a una megagranja de su territorio.

En específico, resaltó la participación de niñas y niños de Homún, quienes han sido considerades como sujetos de lucha al contemplar su participación y voz en la defensa de su territorio y quienes fueron fundamentales en el juicio interpuesto contra PAPO al denunciar 


\section{LÓPEZ-FABILA, A.}

el riesgo que representaba el proyecto para su derecho a un medio ambiente sano y por el derecho como integrantes de una comunidad indígena. Su participación fue esencial ya que amparo fue determinante para la suspensión de las actividades de la granja. Sobre esa experiencia Martina, habitante de Homún relata que "los niños que hicieron sus cartitas, niños que hicieron sus dibujitos donde decían que no querían a la granja, que no quieren agua contaminada. Y ese amparo fue el que se ganó que de hecho se sigue reforzando para que ya no se abra la granja" (entrevista, marzo de 2020). El reconocimiento del aporte que niños y niñas han tenido en esta lucha es relevante para el surgimiento de estrategias creativas que incorporan a la infancia a los espacios públicos y en la toma de decisiones. La defensa de la vida desde la experiencia de la niñez como señala Torres (2013) al hablar sobre la participación de niños y niñas en pueblos indígenas que luchan por su autonomía es "de la misma magnitud que el de los adultos, en tanto proporción acorde a roles y saberes" su participación hace que se construya su subjetividad desde la propia singularidad de niños y niñas indígenas desde el reconocimiento en la colectividad como pueblos.

Otra forma de movilización contra la imposición y las afectaciones sobre los cuerpos y territorios al pueblo maya por los proyectos de la industria porcícola fue la acción que pobladores de las comunidades de Kinchil y Homún junto con la organización civil Indignación realizaron en el 2019 durante el día mundial del medio ambiente. La movilización señaló y reconoció al Grupo empresarial Porcícola Mexicano alias Kekén y al Grupo Kuo como "Empresa Peligrosamente Racista y Contaminante" obteniendo como distinción garrafas con agua recolectada de los desechos de una de sus granjas. Durante la entrega las y los habitantes mencionaron que este reconocimiento de debía por

"discriminar al pueblo maya, vulnerar el derecho a la consulta, imponer su proyecto económico que es un proyecto extractivista que pone en riesgo nuestros recursos naturales, en particular el agua y los cenotes [...] el proyecto económico que promueve Kekén, la industria a gran escala de cerdos a través de megagranjas, es un proyecto que extrae, para su propio beneficio, grandísimas, enormes cantidades de agua. Sólo la extracción de tal cantidad de agua ya pone en riesgo todo nuestro ecosistema y nuestra vida, pero además lo ha hecho sin consultar a nuestros pueblos, sin respetarnos. Esto para nosotros es racismo y discriminación” (Indignación, 2019).

Más allá de una acción material, la acción representa una forma de resistencia simbólica que desentraña las dimensiones estructurales e institucionales del racismo ambiental que sostienen y reproducen prácticas y discursos implementados por los proyectos extractivistas. En este sentido no solo se responsabiliza a las empresas, sino al entramado político-institucional, donde resalta el papel del Estado mismo que ha servido para garantizar 


\section{LÓPEZ-FABILA, A.}

que las empresas se instalen y produzcan territorios de sacrificio. Es así, que durante la acción, también se reconocieron y señalaron a "colaboradores tóxicos" aquellos políticos, gobiernos, tribunales, jueces y empresa que han sido aliados en el despojo, imposición y daño ambiental que en particular están asumiendo de forma desproporcionada los pueblos indígenas, afrodescentientes, campesinas, prietas.

Esta breve ejemplo de acciones, demandas y movilizaciones que se han desplegado en el contexto contra la agroindustria porcícola podrían enmarcarse en prácticas reflexivas como las describe Gladys Tzul Tzul (2020) que conllevan un principio transformador y una indagación a través del diálogo, donde la potencialidad de los y las sujetas se encuentra en la creación, mantenimiento y transformación de su singularidad. Así como del uso de la performatividad colectiva que sirve como herramienta de movilización.

La organización de las comunidades en articulación con organizaciones como Indignación y Greenpeace aliados en estas luchas, ha sido un motor político importante para visibilizar el tema y sobretodo para exponer la injusticia y el racismo ambiental que más allá de acciones deliberadas tienen lugar en acciones conscientes y discursos explícitos que impactan la reproducción del sostenimiento de la vida. Estos esfuerzos colectivos, comunitarios han tenido logros importantes, actualmente entre agosto y septiembre de 2020 la SEMARNAT rechazo de 6 proyectos de granjas porcícolas promovidos por el Grupo Porcícola Mexicano en los municipios de Tixmehuac y Maní, en Yucatán (Indignación, 2020).

\section{Consideraciones finales}

El impacto diferenciado que sufre la población de Kinchil responsabilidad de las empresas que como Kekén no son asumidas se profundiza y acentúa con falta de infraestructura y de dotación de servicios básicos, lo que evidencia la posición en desventaja que ocupan las comunidades negras, indígenas o de mestizos pobres frente a los proyectos extractivistas en relación al riesgo y vulnerabilidad ambiental. Las formas de racismo ambiental que se ha ejercido sobre la población se enmarcan tanto en la dimensión estructural como institucional. El desplazamiento y exclusión de la población en las decisiones sobre su territorios, hace posible considerar una detrimento de su autonomía territorial que beneficia la configuración de zonas de sacrificio donde las granjas industriales son solo una parte del 
LÓPEZ-FABILA, A.

ensamble extractivista que se ha territorializado en la región y pretende seguir expandiéndose.

Considero que nombrar el el racismo ambiental como parte de la agroindustria porcícola sugiere poner énfasis el los procesos de producción desigual del espacio medias que trae beneficios para las poblaciones blanco-mestizas acosta del daño a las poblaciones indígenas y afrodescendientes. Ante la necesidad de seguir profundizando sobre estas problemáticas se requiere profundizar en los procesos socioespaciales con el objetivo de develar la continuación de patrones históricos ligados al racismo ambiental en los territorios para tener un mayor entendimiento de dichas dinámicas y del panorama de las desigualdades históricas enmarcadas en los procesos extractivistas y con ello tener más herramientas para responder y desmontar las estructuras racistas.

Finalmente, como lo han expresado las comunidades en lucha y resistencia, son los pueblos mayas quienes tienen el derecho y el reconocimiento para decidir, autorizar sobre cualquier proyecto que busque establecerse en su territorio. En este sentido la potencia política de las contranarrativas a la muerte que han desplegado de los diversos pueblos mayas despliega re-existencias múltiples que apuestan por la defensa y el sostenimiento de la vida.

\section{Referencias}

Bolados García, P., Cuevas Sánchez, A., Katta, A., Carolina, O., Castillo, A., y Damann, M. (2017). La ética del cuidado como estrategia frente a la violencia extractivista entre las Mujeres de Zonas de Sacri fi cio en Resistencia ( Zona Central, Chile ). Ecología Política. Cuadernos de Debate Internacional, 83-88.

Borde, E., y Torres-Tovar, M. (2017). El territorio como categoría fundamental para el campo de la salud pública. Saúde em Debate, 41(spe2), 264-275. https://doi.org/10.1590/0103-11042017s222

Cevallos, S., y Cevallos, F. (2018). Cartografía colonial y racismo socio-ambiental: el caso de los pueblos Tagaeri y Taromenane en el Parque Nacional Yasuní en Ecuador. Iberoamérica Social: Revista-red de estudios sociales, A. 6(11), 112-129.

Colectivo Miradas Críticas del Territorio desde el Feminismo. (2017). Mapeando el cuerpoterritorio: Guía metodológica para mujeres que defienden sus territorios.

Composto, C., y Navarro, M. L. (2014). Territorios en disputa. Despojo capitalista, luchas en defensa de los bienes comunes naturales y alternativas emancipatorias para América Latina. Claves de lectura para comprender el despojo y las luchas por los bienes comunes naturales en América Latina.

De Oliveira Pires, Thula Rafaela; Totti Guimaraes, V. (2001). Injusticia ambiental , racismo 
LÓPEZ-FABILA, A.

ambiental y el marco para la estratificación socio-racial en zonas de sacrificio : el caso del barrio de Santa Cruz en Rio de, 1-23.

2020. Descolonización ante el racismo ambiental y el ecologismo blanco. En Descolonizar el ecologismo. LaReci Ediciones

Drucker, A. G., Escalante Semerena, R. I., Gómez González, V., y Magaña Rueda, S. (2004). La industria porcina en Yucatán:un análisis de la generación de aguas residuales. Problemas del Desarrollo. Revista Latinoamericana de Economía, 34(135), 105-124. https://doi.org/10.22201/iiec.20078951e.2003.135.7505

Druker et al 2004 Aguas residuales porcinas.pdf. (s/f).

Figueroa, M. G. M. (2016). El archivo del estudio del racismo en México/An Archive of the Study of Racism in Mexico. Desacatos, (51), 92-107,223. Recuperado a partir de http://search.proquest.com/docview/1812273925? accountid=26837\%5Cnhttp://sfxexpre ss.exlibrisgroup.com:3210/express2-colmex ?url_ver=Z39.88-

2004\&rft_val_fmt=info:ofi/fmt:kev:mtx:journal\&genre=unknown\&sid=ProQ:ProQ\%3A socscijournals\&atitle $=\mathrm{El}+\operatorname{archivo}+\mathrm{del}+\mathrm{estu}$

Firpo Porto, M., Pacheco, T., y Leroy, J. P. (2013). Injustiça ambiental e saúde no Brasil: o Mapa de Conflitos. Injustiça ambiental e saúde no Brasil: o Mapa de Conflitos. https://doi.org/10.7476/9788575415764

Flores, A., y Deniau, Y. (2019). El megaproyecto para la península de Yucatán, 41. Recuperado a partir de http://geocomunes.org/Analisis_PDF/AnalisisGeneralYucatan.pdf

GREENPEACE. (2020). ¿Qué hay detrás de la industria porcícola en la península de Yucatán?La carne que está consumiendo al Planeta.

Machado Aráoz, H. (2013). Crisis ecológica, conflictos socioambientales y orden neocolonial: Las paradojas de NuestrAmérica en las fronteras del extractivismo. Rebela. Revista Brasilera de Estudios Latinoamericanos (Vol. 3).

Mbembe, A. (2003). "Necropolitics". Public Culture 15 (1): 11-40.

Moreno Parra, M. (2019). Racismo ambiental: muerte lenta y despojo de territorio ancestral afroecuatoriano en Esmeraldas TT - Environmental Racism: Slow Death and the Displacement of Ancestral Afro-Ecuadorian Territory in Esmeraldas TT - Racismo ambiental: morte lenta e desapro. Íconos. Revista de Ciencias Sociales, (64), 89-109. Recuperado a partir de http://scielo.senescyt.gob.ec/scielo.php?script= sci_arttext\&pid=S1390-12492019000200089\&lang=pt\%0Ahttp:// none/pdf/iconosfl/n64/1390-8065-iconosfl-64-89.pdf

Novelo, M., Borges, C., Borges, V., Pérez, B., Peraza, C., Canul, P., y Vivas, G. (2009). Estimación del potencial contaminante de las granjas porcinas y avícolas del estado de Yucatán Estimation of the polluting potential of poultry and swine farms in the State of Yucatan. Ingeniería, Revista Académica de la FI-UADY, 13(12), 13-21.

Pacheco Ávila, J., y Cabrera Sansores, A. (2003). Artículo de Divulgación Fuentes principales de nitrógeno de nitratos en aguas subterráneas. Ingeniería, 7(2), 47-54.

Pulido, L. (2000). Rethinking environmental racism: White privilege and urban development 


\section{LÓPEZ-FABILA, A.}

in southern California. Annals of the Association of American Geographers, 90(1), 12 40. https://doi.org/10.1111/0004-5608.00182

Rodríguez-León, L. D., Ordoñez-Vásquez, K. M., y Quizhpe-Cordero, P. F. (2019).

Estrategias para mitigar el impacto ambiental generado por la porcicultura hacia la contribución del desarrollo sostenible: Sitio Banasur, cantón Pasaje. Polo del Conocimiento, 4(8), 51. https://doi.org/10.23857/pc.v4i8.1043

Torres, E. (2013). La participación de niños y niñas en pueblos indígenas que luchan por su autonomía. Rayuela: Revista Iberoamericana, 7, 105-113.

Vela-Almeida, D., Zaragocín, S., Bayón, M., y Arrazola, I. (2020a). Imaginando territorios plurales de vida: una lectura feminista de las resistencias en los movimientos socioterritoriales en el Ecuador. Journal of Latin American Geography, 19(2), 87-109. https://doi.org/10.1353/lag.2020.0029

Vela-Almeida, D., Zaragocín, S., Bayón, M., y Arrazola, I. (2020b). Imaginando territorios plurales de vida: una lectura feminista de las resistencias en los movimientos socioterritoriales en el Ecuador. Journal of Latin American Geography, 19(2), 87-109. https://doi.org/10.1353/lag.2020.0029

Wallace, R. (2016). Big Farms Make Big Flu. Dispatches on Infectious Disease, Agribusiness, and the Nature of Science. Monthly Review Press. Recuperado a partir de https://libgen.pw/item?id=1549646\&adblock=true

Zaragocin, S. (2020). La geopolítica del útero : hacia una geopolítica feminista decolonial en espacios de muerte lenta ., (January). 